\title{
The strength analysis of no power bogie in rail-defect detector car
}

$$
\text { Jijun Gong }{ }^{1, a} \text {, Pingbo } \mathrm{Wu}^{2, \mathrm{~b}} \text { and Bo } \mathrm{Hou}^{2, \mathrm{c}}
$$

${ }^{1}$ State Key Traction Power Laboratory of Southwest Jiaotong University, Chengdu 610031, China;

${ }^{2}$ State Key Traction Power Laboratory of Southwest Jiaotong University, Chengdu 610031, China.

a18384124476@163.com, bwupingbo@163.com, ${ }^{\mathrm{c}}$ houboswjtu @163.com

Keywords: Strength analysis, Rail-defect, Simulation, Finite element, Fatigue, Infinite life.

\begin{abstract}
Rail-defect detector car compared with the artificial detection device has many advantage. This paper presents a certain type of rail-defect detector vehicle bogie's Strength analysis. The finite element analysis software ABAQUS is used to setup the finite element model of bogie frame and analyze frame strength. Calculation results show that the structure can satisfy the strength requirements of the frame and fatigue assessment results show that the structure satisfied the infinite life design criteria.
\end{abstract}

\section{Introduction}

The software ABAQUS is used to conduct the FEM analysis of the bogie frame. It can make errors between the FEM model and the designed structure smaller and the results closer to the reality. The solution scale of the abaqus is larger, have cases to build up the entire unit finite element model which has the smaller grid unit. The model is built in $3 \mathrm{~d}$ model, through modeling and local simplified by the computer automatic discrete, then loading load in finite element calculation. The load case for bogie frame are determined according to UIC515-4 "Tractive units-Bogies and running gear-Bogie frame structure strength tests".

\section{The calculation of the frame allowable stress and the cases of use}

The allowable stress of material is equal to the quotient of the yield limit $\sigma_{\mathrm{s}}$ and safety factor S. Q345C welded-steel plate construction is mainly applied to the frame in designing, the yield limit of the material is $345 \mathrm{MPa}$.

According to UIC515-4, for complex mechanical components, need to calculate the equivalent stress（Von Mises stress）, this stress shall not exceed the allowable stress. This calculation stress results are all using equivalent stress. The formula of the equivalent stress is

$$
\sigma_{e}=\sqrt{0.5\left[\left(\sigma_{1}-\sigma_{2}\right)^{2}+\left(\sigma_{2}-\sigma_{3}\right)^{2}+\left(\sigma_{3}-\sigma_{1}\right)^{2}\right]}
$$

In this calculation, the allowable stress of Q345C welded-steel plate construction is $216 \mathrm{MPa}$ in operation, it's 314MPa while in extraordinary cases.

\section{The frame finite element model}

Based on the structure characteristics of the frame, it divided into solid element. Using ABAQUS finite element mesh tetrahedral partition technology, the frame is divided into 270640 units.

Considering the frame is supported on the axle-box spring-bearing, establish spring boundary element on the surface of each support, vertical, horizontal and vertical stiffness of the spring boundary element correspond with three direction stiffness of primary suspension; Spring boundary units are totally 24.In the model, $\mathrm{X}$ coordinate for the direction of the vehicle, $\mathrm{Y}$ coordinate for vertical upward direction and $\mathrm{Z}$ coordinate for transverse direction.

After the discrete, finite element calculate and load model is shown in figure, local finite element model is shown in figure 2. 


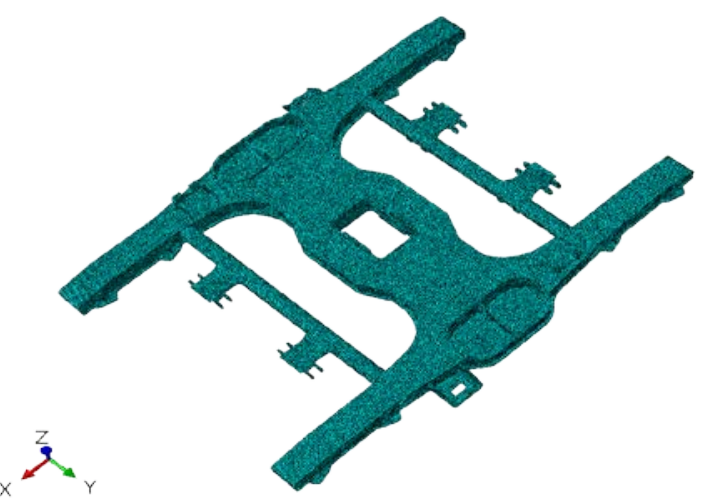

Fig.1 The frame finite element model

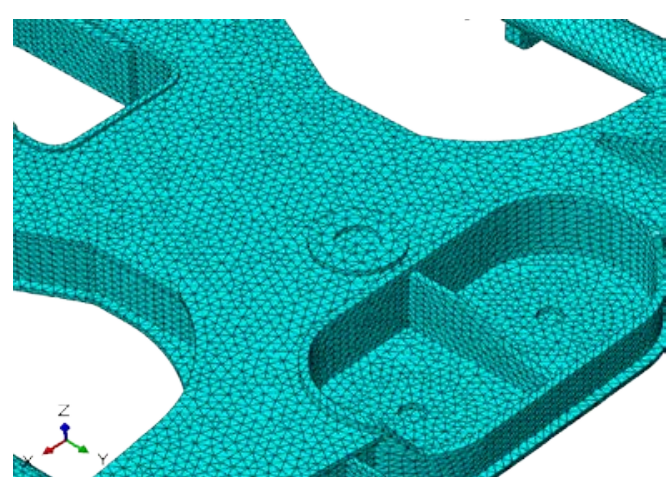

Fig.2 The frame local finite element model

\section{The main computation load and calculation case of the frame finite element model}

\subsection{The main computation load of the frame finite element model}

As space is limited, the detailed derivation process is not given. According to the request of UIC515-4, we can get them easily.

The vertical load of the frame is $66.87 \mathrm{kN}$.

The vertical load considering drifting and side-rolling. We can easily figure out

$$
\begin{array}{ll}
F_{Z 1}=F_{Z}(1-\alpha-\beta)=46.81 k N & F_{Z 2}=F_{Z}(1+\alpha-\beta)=60.18 k N \\
F_{Z 3}=F_{Z}(1-\alpha+\beta)=73.56 k N & F_{Z 4}=F_{Z}(1+\alpha+\beta)=86.93 k N
\end{array}
$$

The extraordinary vertical load on each side of frame: $F_{Z 1 \max }(N)=F_{Z 2 \max }(N)==137.21 \mathrm{kN}$. The calculated operation lateral load of each frame is $48.24 \mathrm{kN}$. The calculated extraordinary lateral load of each frame is $86.19 \mathrm{kN}$. The calculated traction load is $16.77 \mathrm{kN}$. The braking load is $14.29 \mathrm{kN}$. The simulation operation skew symmetrical load is $6.25 \mathrm{~mm}$. The extraordinary skew symmetrical load is $12.50 \mathrm{~mm}$. The second vertical damper load is $10.8 \mathrm{kN}$. The second lateral damper load is $3.6 \mathrm{kN}$.The simulation operation rhombus load is $9.64 \mathrm{kN}$.

\subsection{The calculation case of the frame finite element model}

\subsubsection{The frame simulation operation cases}

The finite element calculation cases have been given in table 1. Due to the limited space, calculated value is not given.

Table 1 Selected simulation operation finite element model calculation cases

\begin{tabular}{|c|c|}
\hline cases & Simulation operation combination description \\
\hline 1st case & Vertical \\
\hline 2nd case & Vertical + traction \\
\hline 3rd case & Vertical+ longitudinal traction + brake \\
\hline 4th case & Vertical + the three-direction stop (positive)+ traction+ track distortion + vertical, lateral \\
damper + longitudinal rhombus load
\end{tabular}




\subsubsection{The frame extraordinary load cases}

The finite element calculation cases have been given in table 2. Due to the limited space, calculated value is not given.

Table 2 Selected the frame extraordinary load finite element calculation cases

\begin{tabular}{|c|c|c|}
\hline Load & case & Combination description \\
\hline \multirow{5}{*}{$\begin{array}{l}\text { Extraordina } \\
\text { ry load }\end{array}$} & 1st case & Extraordinary vertical, $\mathrm{k}=2.0$ \\
\hline & 2nd case & Extraordinary vertical, $\mathrm{k}=1.4+$ extraordinary lateral \\
\hline & 3rd case & $\begin{array}{c}\text { Extraordinary vertical, } \mathrm{k}=1.4+\text { extraordinary lateral } \\
\text { (negative ) }\end{array}$ \\
\hline & 4th case & $\begin{array}{c}\text { Extraordinary vertical, } \mathrm{k}=1.4+\text { extraordinary lateral }+ \\
\text { extraordinary distortion }\end{array}$ \\
\hline & 5th case & $\begin{array}{c}\text { Extraordinary vertical, } \mathrm{k}=1.4+\text { extraordinary lateral } \\
\text { (negative })+ \text { extraordinary distortion }\end{array}$ \\
\hline $\begin{array}{l}\text { Special } \\
\text { extraordinary }\end{array}$ & 1st case & Three-point support,low-speed derailment \\
\hline
\end{tabular}

\subsection{Static strength calculation of the frame}

\subsubsection{Simulation operation load cases}

From table 3,we can easily get the maximum von Mises stress under simulation operation load cases. The charts show that the maximum von Mises stress of the frame under simulation operation cases is $105.70 \mathrm{MPa}$, appearing on the second spring seat plate edge.

Table 3 The maximum von Mises stress of simulation operation cases

\begin{tabular}{|c|c|c|}
\hline cases & $\begin{array}{c}\text { The maximum von Mises } \\
\text { stress }(\mathrm{MPa})\end{array}$ & The maximum von Mises stress locations \\
\hline 1st case & 77.84 & the second spring seat plate edge \\
\hline 2nd case & 78.16 & the second spring seat plate edge \\
\hline 3rd case & 96.31 & beams and side frame connections \\
\hline 4th case & 91.99 & the second spring seat plate edge \\
\hline 5th case & 91.35 & the second spring seat plate edge \\
\hline 6th case & 104.80 & the second spring seat plate edge \\
\hline 7th case & 105.70 & the second spring seat plate edge \\
\hline 8th case & 104.80 & the second spring seat plate edge \\
\hline 9th case & 105.70 & the second spring seat plate edge \\
\hline
\end{tabular}

\subsubsection{The frame extraordinary and special extraordinary load cases}

The table 4 show the maximum von Mises stress under extraordinary and special extraordinary load cases. The charts show that the maximum von Mises stress of the frame under extraordinary and special extraordinary load cases is $159.9 \mathrm{MPa}$,appearing in extraordinary vertical, on the second spring seat plate edge. 
Table 4 The maximum von Mises stress of extraordinary and special extraordinary load cases

\begin{tabular}{|c|c|c|c|}
\hline \multirow{2}{*}{ Load } & case & $\begin{array}{c}\text { The maximum von Mises } \\
\text { stress }(\mathrm{MPa})\end{array}$ & The maximum von Mises stress locations \\
\hline \multirow{5}{*}{ Extraordinary load } & 1st case & 159.70 & the second spring seat plate edge \\
\cline { 2 - 4 } & 2nd case & 114.80 & the second spring seat plate edge \\
\cline { 2 - 4 } & 3rd case & 114.70 & the second spring seat plate edge \\
\cline { 2 - 4 } & 4th case & 128.80 & the second spring seat plate edge \\
\hline Special extraordinary & The case & 128.80 & the second spring seat plate edge \\
\hline
\end{tabular}

\section{The fatigue strength evaluation of frame simulation operation cases}

Vehicle bearings usually work under three stress states. The research report OREB13.5/RP17 from UIC experiment research center and the paper about the structure fatigue show that, the direction of the structure to produce fatigue crack and the maximum principal stress direction perpendicular to each other. According to the significant structure fatigue characteristics, three stress state is converted into unidirectional stress state, calculate the average stress cycle stress and stress amplitude, then judge the structural fatigue strength by the manufacturing material modified Goodman curve.

Modified Goodman fatigue limit diagram is actually a kind of fatigue damage stress envelope. The using method is: If any stress points in the polygon above or beyond, it means that after the specified circulation $\mathrm{N}$ fatigue or fatigue after a $\mathrm{N}$ time, material will break. If stress points in the polygon, then after a specified cycle $\mathrm{N}$ fatigue or fatigue after a $\mathrm{N}$ time, material is safe. So, a stress point in the polygon is safe. So, the points located in the polygon are safe.

\subsection{Load conditions established}

This article load conditions established according to the rule about working condition of frame structure in UIC515-4"Tractive units-Bogies and running gear-Bogie frame structure strength tests", set its fatigue loading conditions.

\subsection{Load Material Smith-Goodman fatigue curve and bogie frame fatigue strength evaluation}

According to the information about bogie frame structure material provided by the manufacturer, frame adopts Q345 weathering steel, so we draw two material Smith-Goodman fatigue curve considering the safety factor $k=1.5$ and $k=1.65$.The main parameter is showing here: $\sigma b=480 \mathrm{Mpa}$, $\sigma \mathrm{s}$ $=345 \mathrm{Mpa}, \sigma 1=222.75 \mathrm{Mpa}$. Tensile strength and yield strength are given in the standard, fatigue characteristics obtained by empirical formula calculation. Each respectively consider parent metal and weld in the process of drawing curves of two kinds of Goodman, see Figure 5.。

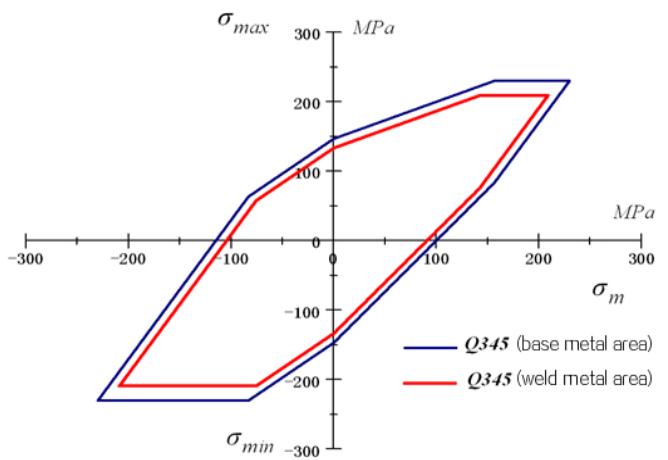

Fig.3 Goodman curve of bogie frame materials

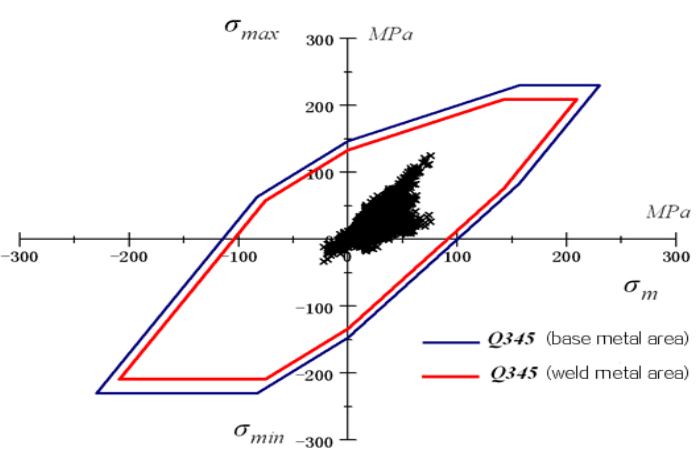

Fig.4 No power bogie frame fatigue evaluation

Rreferences to the condition of table 7,we evaluate the fatigue of the no power bogie frame. Seen from the figure 4,all nodes in the power bogie frame, finite element model of mean stress and maximum and minimum principal stress value are included in the smallest envelope, it shows that the power bogie frame design meet the requirements of infinite life design criteria. 


\section{Summary}

Through the static strength test and the fatigue strength test of the bogie frame, we can easily obtain the following conclusions:

Among the calculation cases required by UIC515-4, the maximum von Mises stress of the frame is $105.70 \mathrm{MPa}$, in simulation operation cases, not exceeded the material allowable stress 216MPa under operation conditions standard. And in the extraordinary cases, the maximum von Mises stress is $159.70 \mathrm{MPa}$, not exceeded the material allowable stress $314 \mathrm{MPa}$ under extraordinary cases standard.

According to the figure Goodman for the frame fatigue strength assessment from UIC515-4, the power bogie frame design meet the requirements of infinite life design criteria.

\section{Acknowledgements}

This work has been supported by the China Railway Corporation scientific research and development projects (project No. 2014J012-C and project No. 2014J008-A) and the Chinese National Science Foundation (project No. 51205325).

\section{References}

[1] Er-guang CUI, Zi-ming LIU, Fatigue strength evaluation of welded frame, Science Technology and Engineering.Vol.3 (2003) No, 4, p.334-337.

[2] Cai-ying MI, Fu LI, Engineering method of evaluating fatigue strength for welded bogie frame, Diesel Locomotive.Vol.47(2009), p.6-10.

[3] Hong-WANG, Bang-hua,ZHAO, Welding bogie vehicle bearing fatigue strength assessment methods and examples, Rolling Stock. Vol. 5 (1994) No, 5, p.17-22.

[4] Qi AN, Fu LI, Yun-hua HUANG, Fatigue strength assessment for bogie welded frame based on JIS standard, Electric Drive for Locomotives.Vol.4 (2009), p.26-29.

[5] UIC-515-4

[6] Yinhua LIU, et al. The satigue strength and modal analysis of bogie frames for freight cars with variable gauges , Rolling Stock, 2007, 45 (11) ,p.1-4. 